\title{
Further Studies of the Postnatal Change in Chemical Heterogeneity of Human Fetal Hemoglobin in Several Abnormal Conditions
}

\author{
T. H. J. HUISMAN, ${ }^{(23)}$ W. A. SCHROEDER, AUDREY K. BROWN, CAROL B. HYMAN, \\ JORGE A. ORTEGA, AND P. K. SUKUMARAN

\begin{abstract}
Laboratory of Protein Chemistry and Department of Pediatrics, Medical College of Georgia, and Veterans Administration Hospital, Augusta, Georgia; Division of Chemistry and Chemical Engineering, California Institute of Technology, Pasadena, Department of Pediatrics, University of Southern California, School of Medicine, and Division of Hematology-Oncology, Childrens Hospital of Los Angeles, Los Angeles, California, USA; and Cancer Research Institute, Tata Memorial Centre, Parel, Bombay, India
\end{abstract}

Extract

The fetal hemoglobin of 10 infants has been examined serially from birth to several hundred days of age. In the normal child, the ratio of ${ }^{\mathrm{G}} \gamma$ to ${ }^{\mathrm{A}} \gamma$ chain alters from about $7: 3$ at birth to about $2: 3$ at $150-200$ days. In children with abnormalities of hemoglobin synthesis, the ratio changes as expected from data from adults with the particular abnormality. Thus, little change in ratio was shown by two $\beta$-thalas. semia homozygotes, whereas two $\beta$-thalassemia heterozygotes showed the same behavior as a normal child; the latter behavior is expected from one of the two classes of $\beta$-thalassemia heterozygotes. A heterozygote from the ${ }^{\mathrm{G}} \gamma^{\mathrm{A}} \gamma$ class of hereditary persistence of fetal hemoglobin behaved much like a normal child, but two heterozygotes from the ${ }^{\mathrm{G}} \gamma$ class showed the expected change from approximately 9:1 at birth to 10:0 postnatally. Two children with sickle cell anemia resembled a normal child in change of ratio whereas the third, not unexpectedly, did not show a change in ratio.

\section{Speculation}

The mechanisms involved in the gradual change from $\gamma$ chain synthesis to $\beta$ and $\delta$ chain synthesis are complex and ill defined. The results of analyses of the ratio between the products of the ${ }^{\mathrm{G}} \gamma$ and ${ }^{\mathrm{A}} \gamma$ structural genes in infants with distinct genetic disorders at birth and during the postnatal period underscore the complexity of the changeover. However, differences in the postnatal change in the ${ }^{\mathrm{G}} \gamma$ to ${ }^{\mathrm{A}} \gamma$ ratio in infants with an apparent identical condition may help to further define these mechanisms, and to delineate the conditions involved.

The postnatal changeover from the production of hemoglobin $\mathrm{F}$ (Hb-F) to hemoglobin A ( Hb-A) takes a far more complex path than is superficially apparent. The nonallelic structural genes for the $\gamma$ chain of Hb-F (14), of which there may be four (5), appear to be nonsynchronously suppressed (11), with the result that the trace of $\mathrm{Hb}-\mathrm{F}$ in the adult has a different heterogeneity than the $\mathrm{Hb}-\mathrm{F}$ of the newborn child. Thus, in the newborn child, the ratio of ${ }^{\mathrm{G}} \gamma$ to ${ }^{\mathrm{A}} \gamma$ chains (19), on the average, is $7: 3(16)$, whereas it is about $2: 3$ in the traces of $\mathrm{Hb}-\mathrm{F}$ in the adult (12). Examination of $\mathrm{Hb}-\mathrm{F}$ from cord blood and adult blood provides the extremes in these ratios, but serial postnatal examination in single individuals gives information about the behavior of regulatory mechanisms (11). Not only infants with abnormal Hb-F but also neonates with other abnormal conditions of various types have been studied in this way $(11,12)$. We have now been able to examine infants with thalassemia major and trait, with the ${ }^{\mathrm{G}} \gamma$ type of the hereditary persistence of fetal hemoglobin (HPFH), with the ${ }^{\mathrm{G}} \gamma^{\mathrm{A}} \gamma$ type of $\mathrm{HPFH}$, and with sickle cell anemia. Patients with thalassemia major or with sickle cell anemia usually are detected only when medical attention is required. Consequently, little is known about the status of such an individual at birth or about the onset of the diseaae. Present studies provide information about the status of such neonates and their progress, and also test speculations about how the ${ }^{G} \gamma$ to ${ }^{A} \gamma$ ratio should change after birth.

\section{MATERIALS AND METHODS}

\section{SOURCE OF SAMPLES}

EDTA was used as anticoagulant in samples for hematologic examination, and larger samples for isolation of the hemoglobins were placed in EDTA or Alsever's solution.

\section{HEMATOLOGIC DETERMINATIONS}

Hemoglobin concentration, packed cell volume, and erythrocyte and reticulocyte counts were determined by standard methods (18).

\section{ANALYTICAL METHODS FOR HEMOGLOBIN} COMPOSITION

Hemolysates were examined both by starch gel electrophoresis in Tris-EDTA-boric acid buffer at pH 9.0 (2) and by DEAE-Sephadex chromatography for analytic and isolative purposes $(1,4)$. Hemoglobin $\mathrm{F}$ was determined by a procedure which uses the isoleucine content of chromatographically isolated $\mathrm{Hb}-\mathrm{F}$ in its relation to leucine and phenylalanine as the basis for calculation (15). These values are presented as percentage of $\mathrm{F}_{\mathrm{Ile}}$.

\section{CHEMICAL ANALYSIS OF $\mathrm{Hb}-\mathrm{F}$}

The procedure described previously (14) was used to determine the ratio of the two types of $\gamma$ chains in $\mathrm{Hb}-\mathrm{F}$. The 
Table 1. Hematologic and hemoglobin data ${ }^{1}$

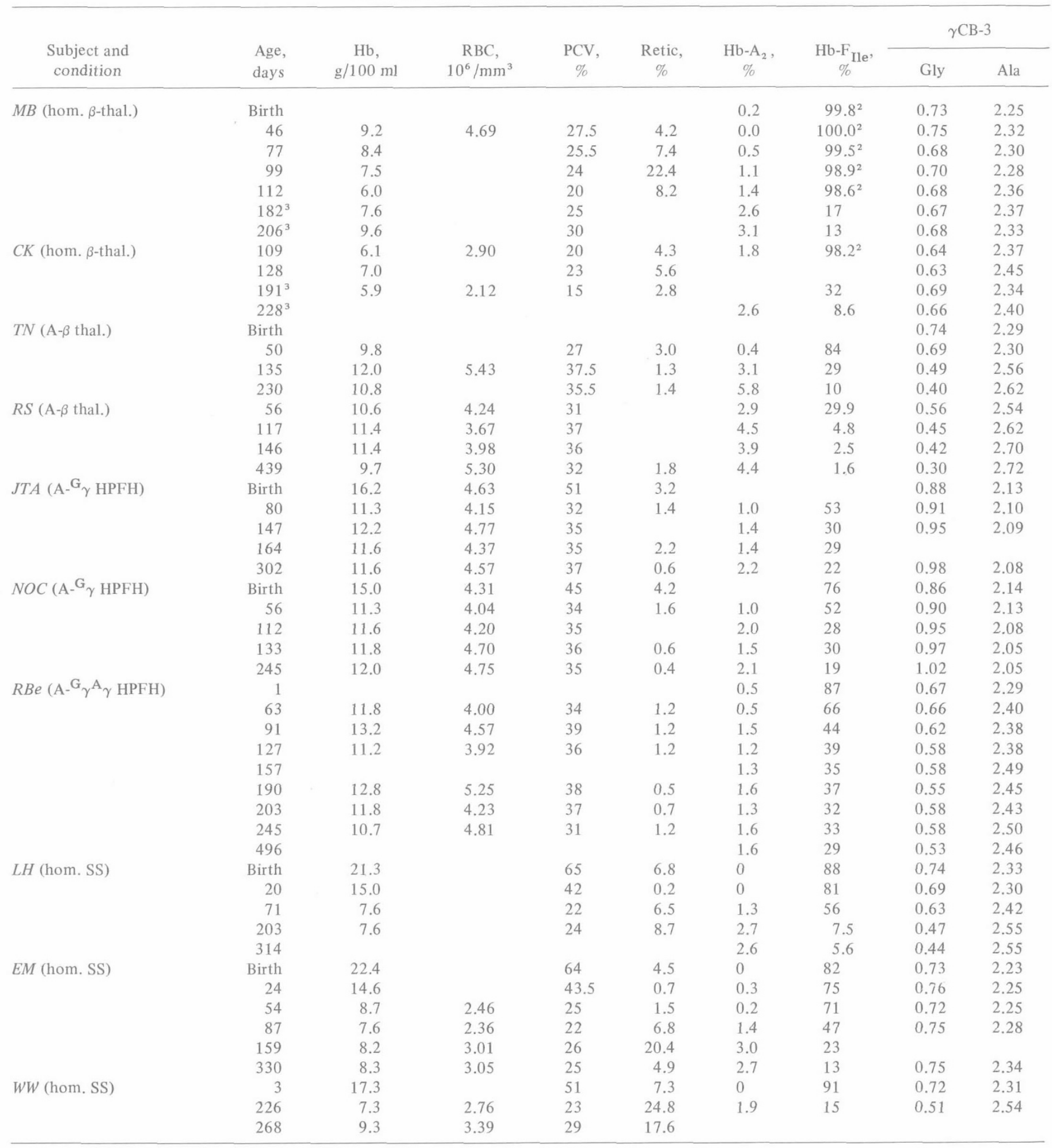

${ }^{1} \mathrm{Hb}$ : hemoglobin; RBC: red blood cell; PCV: packed cell volume; hom.: homozygote; thal.: thalassemia; HPFH: hereditary persistence of fetal hemoglobin.

${ }^{2}$ Assayed by chromatography; no $\mathrm{Hb}-\mathrm{A}$ was detectable before transfusion.

${ }^{3}$ Samples were collected after transfusion. 
data are presented as the number of glycyl and alanyl residues in the carboxy-terminal $\gamma \mathrm{CB}-3$ peptide and are precise to \pm 0.05 residues (8). The meaning of the data is given in Reference 19.

\section{CASE HISTORIES}

Hematnlogic data are presented in Table 1.

\section{THALASSEMIA MAJOR AND TRAIT}

Family B. MB was born August 2, 1971 and weighed 3,120 g. At 42 days of age, she weighed $4,426 \mathrm{~g}$ and was $56.5 \mathrm{~cm}$ long; liver and spleen were not enlarged. At 77 days of age, the liver and spleen were detectable at the costal margin. Because the hemoglobin level had decreased to $6 \mathrm{~g} / 100 \mathrm{ml}$, transfusion of $M B$ was started on the 112th day. Since transfusion was begun, her hemoglobin has been maintained above $10.5 \mathrm{~g} / 100$ $\mathrm{ml}$, and at 2 years of age she receives transfusions every 3 or 4 weeks. The spleen and liver are minimally enlarged. Ironchelating agents have not been given. Growth and development have been normal.

$J B$, a 14-year-old sister, also has $\beta$-thalassemia major. Her parents and two-other siblings have $\beta$-thalassemia trait. The family is of Italian descent.

Family K. CK was born October 30, 1971 and was first seen at the age of 109 days. At that time, the boy was well developed and well nourished with a liver and spleen that were both about $2 \mathrm{~cm}$ below the costal margin. Transfusions were begun at the age of 132 days. He also has been maintained above $10.5 \mathrm{~g} / 100 \mathrm{ml}$ hemoglobin and at 2 years of age, he requires transfusions every $4-5$ weeks. Like $M B$, spleen and liver are minimally enlarged, growth and development are normal, and iron chelating agents have not been given.

His parents are of Greek descent and have the typical stigmata of $\beta$-thalassemia trait.

Family N. TN was born December 9, 1970. Her mother was known to have $\beta$-thalassemia trait, and the child has also developed these characteristics. She has had no significant illnesses that can be attributed to heterozygosity for $\beta$-thalassemia. This child is of Italian descent.

Family $S$. Data from this Negro girl $(R S)$ have been described (12) and are presented again for comparison with those of $T N$.

\section{HEREDITARY PERSISTENCE OF FETAL HEMOGLOBIN}

Family A. JTA was born October 28, 1972 in Bombay. Her mother has the same type of HPFH that JTA has developed, but both are clinically normal. Although the father has not been examined, he probably has $\beta$-thalassemia. This conclusion arises from the fact that $L T A$, a 3 -year-old sibling of $J T A$, is anemic, has mild hepatosplenomegaly, and requires occasional transfusions. LTA is believed to have both HPFH and $\beta$-thalassemia (17).

Family C. NOC was born December 24, 1972 in Bombay. His mother and a 2-year-old sister both have the type of HPFH that he has developed and all of these individuals are clinically normal. His father has $\beta$-thalassemia $\left(\mathrm{Hb}-\mathrm{A}_{2}, 4.8 \%\right)$ and $N O C$ 's 3 -year-old sibling has HPFH- $\beta$-thalassemiá with expression like that of $L T A$ of Family A.

Family Be. RBe was born January 19, 1970. Her mother, uncle, two aunts, and grandmother have the same kind of ${ }^{G} \gamma^{A} \gamma$-type HPFH. This child has been studied repeatedly over the years and some of the data have been presented previously (10), whereas information on her relatives (described as Family E) has been given in an earlier publication (8). Her clinical course has been uneventful.

\section{SICKLE CELL ANEMIA (20)}

Family H. $L H$ was born November 16, 1971 and weighed $.2,850$ g. Her condition wis diagnosed at birth. Severe anemia developed at the age of 2 months. She was admitted repeatedly for infection, and died $4 \mathrm{hr}$ after her last admission on June 7, 1973, of pneumococcal meningitis. Both parents were identified as $\mathrm{Hb}-\mathrm{S}$ heterozygotes.

Family M. EM was born August 13, 1973 and weighed 3,110 g. The disease in this patient was diagnosed at birth. Growth and development were relatively normal, but anemia was noted at 3 months of age. At 6 months of age, the spleen was enlarged. The patient is in reasonable health, and attends the out-patient clinic regularly. Both parents are $\mathrm{Hb}-\mathrm{S}$ heterozygotes.

Family $W$. $W W$ was born March 4, 1972, weighed 3,140 g, and showed a relatively normal growth and development. However, severe anemia was noted at 6 months of age. The patient had a poor attendance at the clinic and died at home in March 1973 of "infection." The mother was identified as a Hb-S heterozygote.

\section{RESULTS}

Although none of the infants who were observed at birth had any physical abnormalities at that time, examination of the hemoglobin from the cord blood of homozygotes for $\beta$-thalassemia and sickle cell anemia showed clear abnormality. Thus, MB with a homozygous $\beta$-thalassemia, and $L H, E M$, and $W W$ with sickle cell anemia had no $\mathrm{Hb}-\mathrm{A}$; indeed, $M B$ had only $\mathrm{Hb}-\mathrm{F}$ and a trace of $\mathrm{Hb}-\mathrm{A}_{2}$ at birth and produced no other hemoglobins whereas the others all had $\mathrm{Hb}-\mathrm{S}$ with $\mathrm{Hb}-\mathrm{A}_{2}$ and $\mathrm{Hb}-\mathrm{F}$. On the other hand, the abnormalities in the other neonates, all of whom are heterozygotes, became apparent only in later samples but were suspected because of the known abnormality in one of the parents.

Figure 1 depicts the chromatographic results of samples from $M B$ with homozygous $\beta$-thalassemia at birth and at 112 days, before transfusion. CK's hemoglobin composition at 109 days was virtually indistinguishable from that of $M B$ at 112 days. Although $M B$ showed little change in hemoglobin composition, anemia became progressively worse.

The other children, despite the variety of their conditions, showed the expected decline of $\mathrm{Hb}-\mathrm{F}$ and increase of an adult

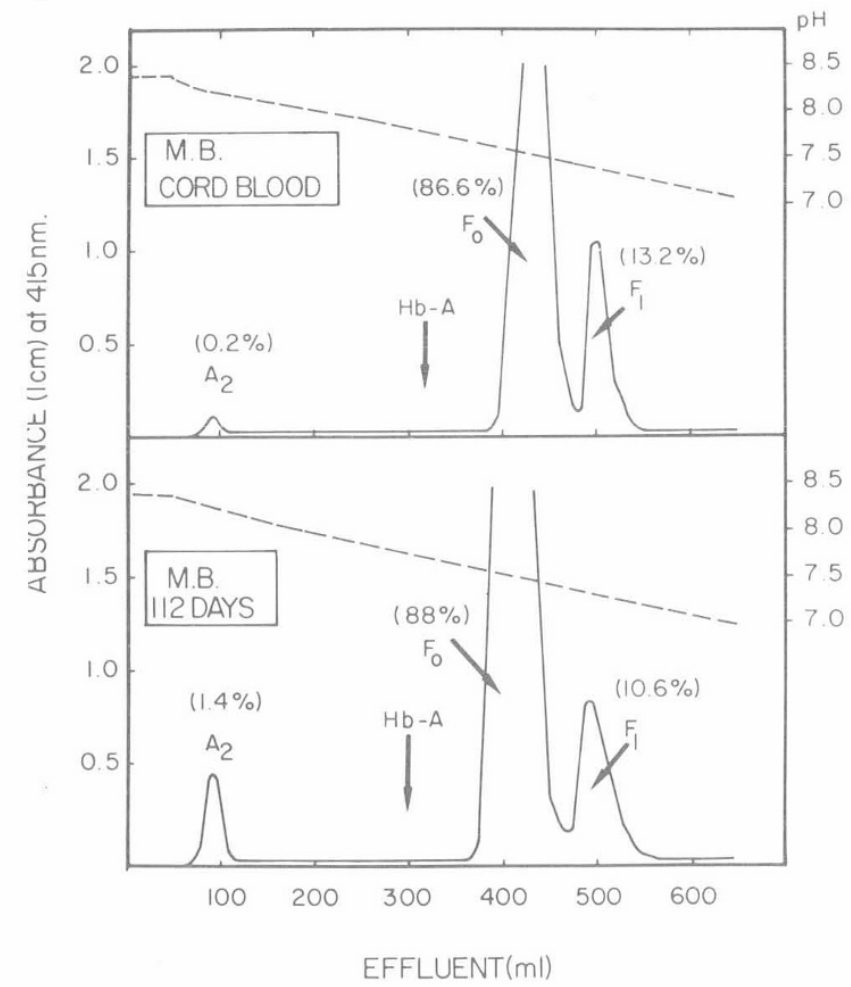

Fig. 1. DEAE-Sephadex chromatograms of the hemoglobins $(\mathrm{Hb})$ of $M B$ who has thalassemia major. 
hemoglobin as well as the onset of anemia if SS disease were present (Table 1). In JTA and NOC, both with a HPFH heterozygosity, the final level of Hb-F may not yet have been reached; it is significantly lower in NOC's mother and 2-year-old sister, namely $11 \%$ and $17 \%$, respectively, but heterozygotes for this type of HPFH show considerable variation in level even within families (17). The Hb-F in $R B e$, the third infant with HPFH trait, at the age of about 500 days has reached the level frequently observed in her mother and other relatives, namely $25-30 \%$. Only in $R S$, heterozygous for $\beta$-thalassemia, did the $\mathrm{Hb}-\mathrm{F}$ decline to almost the adult level within a period of about a year; in the others, $\mathrm{Hb}-\mathrm{F}$ is in higher percentage than in normal children at a comparable age (12).

The chemical examination of $\mathrm{Hb}-\mathrm{F}$ through the determination of the value for glycine in $\gamma \mathrm{CB}-3$ gave data concerning the ratio of the two types of $\gamma$ chain in these patients; the interpretation of these data is given in Reference 19. An average glycine value of 0.7 was observed in 108 normal newborn infants (16). A comparable value was seen at birth in the newborn infants of this study with the exception of JTA and NOC, both with a HPFH heterozygosity, whose values of 0.88 and 0.86 were at the upper limit of the normal range and of $R B e$ whose value of 0.67 was at the lower limit of the normal range. The data for glycine in $\gamma \mathrm{CB}-3$ of various postnatal samples ure recorded in Table 1 and are plotted in Figures 2, 3, and 4 as a function of postnatal age together with the levels of $\mathrm{Hb}-\mathrm{F}$ observed during the same periods. The initially high value in the cases with $\mathrm{G} \gamma$ type of HPFH (JTA and $N O C$ ) rises to 1.0 postnatally and that in the neonate with ${ }^{\mathrm{G}} \gamma^{\mathrm{A}} \gamma$ type of HPFH decreases only slightly. The value in the two $\beta$-thalassemia heterozygotes, $T N$ and $R S$, as well as the two SS patients, $L H$ and $W W$, declines to that in the traces of $\mathrm{Hb}-\mathrm{F}$ in the adult. On the other hand, $E M$, another SS patient, has a constant value for glycine in $\gamma \mathrm{CB}-3$ and the two individuals with thalassemia major show a slight decrease.

\section{DISCUSSION}

The results of this investigation are in basic accord with those that were anticipated from previous information about $\mathrm{Hb}-\mathrm{F}$ in these conditions. This discussion will consider each category of disease separately.

\section{$\beta$-THALASSEMIA (FIG. 2)}

The effect of a $\beta$-thalassemia mutation is a reduction in the production of $\beta$ chains and consequently of hemoglobin $\mathrm{A}$. The consequences in the heterozygote are minor but, in the homozygote, a severe anemia usually develops with attendant bone changes, organomegaly, failure to thrive, and often death in early childhood. Different variants of $\beta$-thalassemia exhibit a varying imbalance in chain synthesis (see Reference 3 for references). There is no doubt that $M B$ and $C K$ suffer from the most severe type, the so-called $\beta^{\circ}$-thalassemia, without detectable production of $\beta$ chains and inadequate compensatory production of $\gamma$ chains. Within 3-4 months after birth, they developed a severe anemia which required transfusion for survival. The chromatographic analyses for hemoglobin composition were important for evaluating the genetic condition in these infants who were potential homozygotes because their parents were heterozygotes. These analyses, although decisive in these neonates, cannot be used universally for the diagnosis of $\beta$-thalassemia major at birth because homozygous neonates with only a partial suppression of $\beta$ chain production will have $\mathrm{Hb}-\mathrm{A}$ and may not, therefore, be strikingly abnormal.

There is a slight but hardly significant decrease in glycine of $\gamma \mathrm{CB}-3$ in postnatal samples from $M B$. Although the $\gamma \mathrm{CB}-3$ of $C K$ was first examined at the age of 109 days, the data at that age and later are almost identical with those of $M B$. The values are not influenced by transfusions. Their glycine values of approximately 0.65 as well as that of 0.60 for $M B$ 's sibling
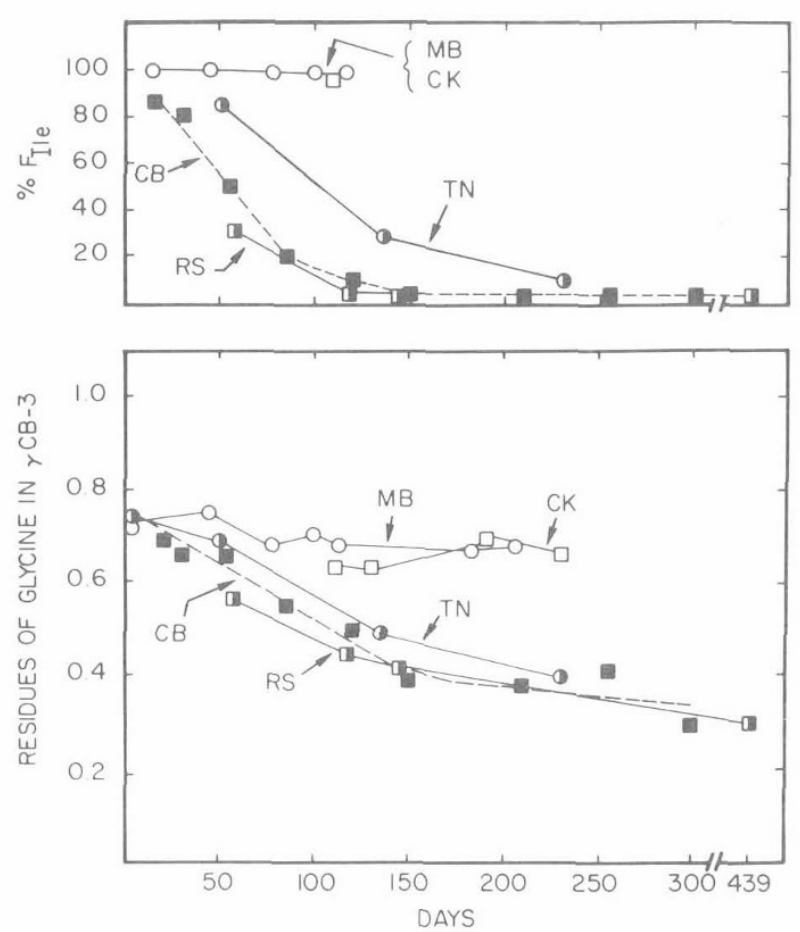

Fig. 2. Values for glycine in $\gamma \mathrm{CB}-3$ and for total hemoglobin $\mathrm{F}$ as a function of postnatal age in $\beta$-thalassemia. $M B$ and $C K$ are infants with homozygous $\beta$-thalassemia. $R S$ and $T N$ are infants with heterozygous $\beta$-thalassemia. The data on $\mathrm{CB}$ with a hemoglobin $\mathrm{C}$ trait are from Reference 12 .

who also has thalassemia major are comparable with data from many adults with thalassemia major (9). $M B$ 's parents have glycine values that approximate that in $\mathrm{Hb}-\mathrm{F}$ of the normal adult. This is typical of one of the two classes that are observed with $\beta$-thalassemia heterozygotes $(9,13)$; in the other class, the glycine value approximates that in $\mathrm{Hb}-\mathrm{F}$ of the newborn infant.

On the other hand, the heterozygotes, $T N$ and $R S$, have a progressive postnatal decline in the value of glycine in $\gamma \mathrm{CB}-3$. The final value is much like that of the parents of $M B$ and places them in the same class. If either of these heterozygotes had been in the other class, their glycine value would have been about $0.70-0.75$ at birth and would have remained essentially constant in postnatal life.

\section{HEREDITARY PERSISTENCE OF FETAL HEMOGLOBIN (FIG. 3)}

The HPFH condition may be subdivided into three major types: the ${ }^{G} \gamma$ type, the ${ }^{A} \gamma$ type, and the ${ }^{G} \gamma^{A} \gamma$ type in which, respectively, the Hb-F has only ${ }^{\mathrm{G}} \gamma$ chains, only ${ }^{\mathrm{A}} \gamma$ chains, or both (see Reference 3 for summary). Infants JTA and NOC belong obviously to the ${ }^{G} \gamma$ type: their Hb-F, which at birth contained both ${ }^{\mathrm{G}} \gamma$ and ${ }^{\mathrm{A}} \gamma$ chains, has only ${ }^{\mathrm{G}} \gamma$ chains in the $\mathrm{Hb}-\mathrm{F}$ that persists in adult life. Infant $R B e$ belongs to the ${ }^{G} \gamma^{A} \gamma$ type.

In the normal child, the activity of both ${ }^{\mathrm{G}} \gamma$ and ${ }^{\mathrm{A}} \gamma$ genes is suppressed postnatally, and their ratio of production is altered. In $J T A$ and $N O C$, we observe the suppression of the ${ }^{\mathrm{G}} \gamma$ and A $\gamma$ chain loci on the normal chromosome, whereas the suppression of $\gamma$ chain loci on the abnormal chromosome which has the HPFH determinant is less complete and does not involve one of the ${ }^{\mathrm{G}} \gamma$ loci. As a result, the ${ }^{\mathrm{A}} \gamma$ chain disappears from the $\mathrm{Hb}-\mathrm{F}$ and the persistent $\mathrm{Hb}-\mathrm{F}$ has only ${ }^{\mathrm{G}} \gamma$ chains. The various classes of HPFH have been considered to result from deletions of $\delta, \beta$, and one or more $\gamma$ loci (see Reference 9 for a detailed discussion). In these two children, the deletion would involve the $\delta, \beta$, and ${ }^{\mathrm{A}} \gamma$ loci. Because of the production 

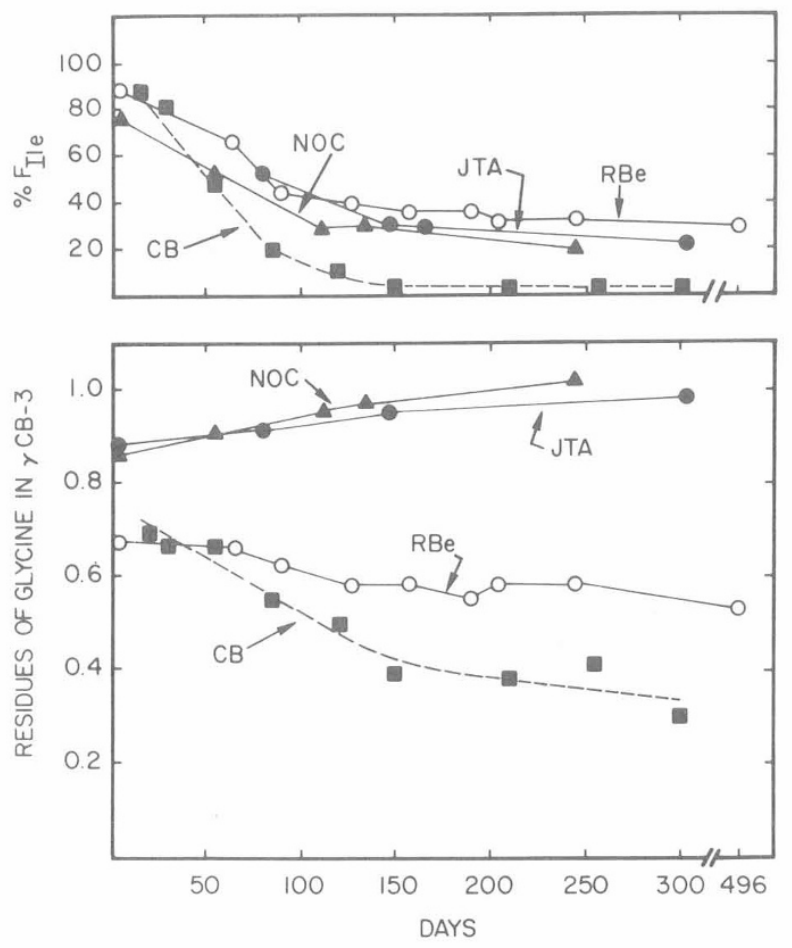

Fig. 3. Values for glycine in $\gamma \mathrm{CB}-3$ and for total $\mathrm{Hb}-\mathrm{F}$ as a function f postnatal age in hereditary persistence of fetal hemoglobin (HPFH). $T A$ and $N O C$ have a $\mathrm{G}_{\gamma}$ type of HPFH trait and $R B$ has a ${ }^{G_{\gamma}} \mathrm{A}_{\gamma}$ type f HPFH trait. The data on $C B$ with a hemoglobin $C$ trait are from eference 12 .

f $\gamma$ chains from the normal chromosome is suppressed almost) completely and that from the abnormal is at most artly suppressed, the deletion must also involve one or more sgulatory factors. It appears that this factor which is still cated on the normal chromosome can suppress $\gamma$ chain roduction in cis but cannot control the ${ }^{G} \gamma$ chain production 1 trans on the abnormal chromosome. Regulatory factors in le complex of $\delta, \beta$, and $\gamma$ loci are considered in detail in eference 9.

Similar considerations are valid for the infant $R B e$ with the $\gamma^{\mathrm{A}} \gamma$ type of HPFH. The production of ${ }^{\mathrm{A}} \gamma$ and ${ }^{\mathrm{G}} \gamma$ chains om the normal chromosome is suppressed (almost) comletely but ${ }^{\mathrm{A}} \gamma$ and ${ }^{\mathrm{G}} \gamma$ chain production from the abnormal hromosome continues because the deletion involves $\delta$ and $\beta$ hain structural loci and presumably no $\gamma$ chain structural loci. gain it can be assumed that the deletion includes one or more gulatory factors. Unexplained is the relatively high glycyl vel $(0.53-0.60)$ which is observed in this infant and also in er relatives (8). This level is significantly higher than the most ommon value of about $0.3-0.45$ in the ${ }^{\mathrm{G}} \gamma^{\mathrm{A}} \gamma$ type of HPFH. Further consideration of regulatory factors may be made on 1e basis of data from JTA's sibling LTA. LTA presumably has $1 \mathrm{e}^{\mathrm{G}} \gamma$ type of $\mathrm{HPFH}$ and $\beta$-thalassemia and produces $\mathrm{Hb}-\mathrm{F}$ ith glycine of 0.81 and alanine of 2.18 in $\gamma$ CB-3 (17). When a ombination of $\beta$-thalassemia with the ${ }^{\mathrm{A}} \gamma$ type of HPFH (10) $r$ the ${ }^{\mathrm{G}} \gamma^{\mathrm{A}} \gamma$ type of HPFH (7) is present, the quantity of [b-F is much increased over what would be expected if the ffects of the two genes were simply additive. It has been oncluded $(7,10)$ that the increased $\mathrm{Hb}-\mathrm{F}$ is produced in cis to 1e $\beta$-thalassemia determinant. The same conclusion may be zached from the data on $L T A$. The glycine value of 0.81 in is $\gamma$ CB-3 means that both $\mathrm{G}_{\gamma}$ and $\mathrm{A}_{\gamma}$ chains are present. ecause the HPFH determinant produces only ${ }^{\mathrm{G}} \gamma$ chains, the $\gamma$ chains must derive from the presumed $\beta$-thalassemia eterminant. The sample of hemoglobin from $L T A$ that was xamined contained only a few percent of $\mathrm{Hb}-\mathrm{A}$ which may ave been the residue of a prior transfusion. This suggests that $\beta^{\circ}$-thalassemia is present. It may also be calculated in the manner described previously $(7,10)$ that the $\mathrm{Hb}-\mathrm{F}$ from this thalassemia is the kind that would have a glycine value of about 0.75 in $\gamma \mathrm{CB}-3(9,13)$. Apparently, then, the HPFH determinant (presumably because of deletion of some regulatory factor) is able to stimulate production of $\mathrm{Hb}-\mathrm{F}$ when $\beta$-thalassemia is in trans but not when a normal chromosome is in trans.

\section{SICKLE CELL ANEMIA (FIG. 4)}

The percentage of $\mathrm{Hb}-\mathrm{F}$ in individuals with sickle cell anemia may vary considerably and it is generally considered that higher amounts ameliorate the effects of the disease. In the study of Hb-F in sickle cell anemia (6), there is a tendency for the glycine in $2 \mathrm{CB}-3$ to approximate the value of 0.4 for normal adults. However, a significant number of cases have values of about 0.7 as does the newborn child. Nevertheless, these groupings are not as distinct as in thalassemia (see above). These results are puzzling and would not be the anticipated result of the mutation of a structural gene as the cause of sickle cell anemia is considered to be. However, this study of the three children with sickle cell anemia shows this very effect. The glycine value in $\gamma \mathrm{CB}-3$ of $E M$ changes not at all from the newborn value, whereas that of $L H$ and $W W$ has the expected decline. Although the percentage of $\mathrm{Hb}-\mathrm{F}$ has remained higher in $E M$ than in the others, there is no correlation between quantity of $\mathrm{Hb}-\mathrm{F}$ and glycine value (6).

\section{CONCLUDING DISCUSSION}

These studies bear out the anticipated postnatal behaviors in the glycine value of $\gamma \mathrm{CB}-3$ in infants with an abnormality in hemoglobin synthesis. Thus, in $\beta$-thalassemia homozygotes, glycine in $\gamma \mathrm{CB}-3$ has changed only slightly; it would not be expected to decrease below 0.6 and may approach this as the children mature. Both $\beta$-thalassemia heterozygotes have shown a decline to the adult level of glycine in $\gamma \mathrm{CB}-3$ and, therefore, are shown to be in that subclass of $\beta$-thalassemia heterozygotes $(9,13)$.
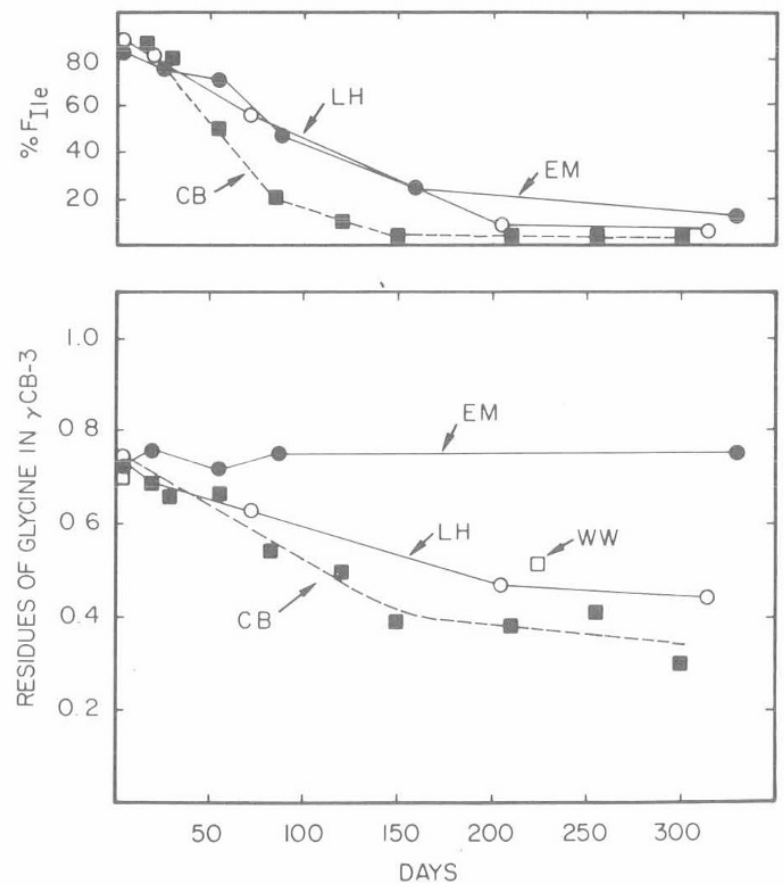

Fig. 4. Values for glycine in $\gamma \mathrm{CB}-3$ and for total hemoglobin $\mathrm{F}$ as a function of postnatal age in sickle cell anemia. $L H, E M$, and $W W$ have sickle cell anemia. The data on $\mathrm{CB}$ with a hemoglobin $\mathrm{C}$ trait are from Reference 12. 
In HPFH heterozygotes, likewise, the behavior follows the anticipated pattern; glycine in $\gamma \mathrm{CB}-3$, already high at birth in the ${ }^{\mathrm{G}} \gamma$ type of HPFH, increases to 1.0 whereas in the ${ }^{\mathrm{G}} \gamma^{\mathrm{A}} \gamma$ type, it decreases to the adult level.

In sickle cell anemia, most adult cases have the adult level and two children exemplify this by levels which decrease to this value. However, the glycine value in $\gamma \mathrm{CB}-3$ of one child has not decreased postnatally, and some adults have also had values similar to those in the neonate.

\section{REFERENCES AND NOTES}

1. Dozy, A. M., Kleihauer, E. F., and Huisman, T. H. J.: Studies on the heterogeneity of hemoglobin. XIII. Chromatography of various human and animal hemoglobin types on DEAE-Sephadex. J. Chromatogr., 32: 723 (1969).

2. Efremov, G. D., Huisman, T. H. J., Smith, L. L., Wilson, J. B., Kitchens, J. L., Wrightstone, R. N., and Adams, H. R.: Hemoglobin Richmond, a human hemoglobin which forms asymmetric hybrids with other hemoglobins. J. Biol. Chem., 244: 6105 (1969).

3. Huisman, T. H. J.: Normal and abnormal hemoglobins. Advan. Clin. Chem., 15: 149 (1972).

4. Huisman, T. H. J., and Dozy, A. M.: Studies on the heterogeneity of hemoglobin. IX. The use of tris(hydroxymethyl)aminomethane HCl buffers in the anion-exchange chromatography of hemoglobins. J. Chromatogr., 19: 160 (1965).

5. Huisman, T. H. J., Schroeder, W. A., Bannister, W. H., and Grech, J. L.: Evidence for four nonallelic structural genes for the $\gamma$ chain of human fetal hemoglobin. Biochem. Genet., 7: 131 (1972).

6. Huisman, T. H. J., Schroeder, W. A., Bouver, N. G., Miller A., Shelton, J. R., Shelton, J. B., and Apell, G.: Chemical heterogeneity of fetal hemoglobin in subjects with sickle cell anemia, homozygous $\mathrm{Hb}-\mathrm{C}$ disease, SC-disease, and various combinations of hemoglobin variants. Clin. Chim. Acta, 38: 5 (1972).

7. Huisman, T. H. J., Schroeder, W. A., Charache, S., Bethlenfalvay, N. C., Bouver, N., Shelton, J. R., Shelton, J. B., and Apell, G.: Hereditary persistence of fetal hemoglobin. Heterogeneity of fetal hemoglobin in homozygotes and in conjunction with $\beta$-thalassemia. New Engl. J. Med., 285: 711 (1971).

8. Huisman, T, H. J., Schroeder, W. A., Dozy, A. M., Shelton, J. R., Shelton, J. B., Boyd, E. M., and Apell, G.: Evidence for multiple structural genes for the $\gamma$ chain of human fetal hemoglobin in hereditary persistence of fetal hemoglobin. Ann. N. Y. Acad. Sci., 165: 320 (1969).

9. Huisman, T. H. J., Schroeder, W. A., Efremuv, G. D., Duma, H., Mladenovski, B., Hyman, C. B., Rachmilewitz, E. A., Bouver, N., Miller, A., Brodie, A. R., Shelton, J. R., Shelton, J. B., and Apell, G.: The present status of the heterogeneity of fetal hemoglobin in $\beta$-thalassemia: An attempt to unify some observations in thalassemia and related conditions. Ann. N. Y. Acad. Sci., in press.

10. Huisman, T. H. J., Schroeder, W. A., Stamatoyannopoulos, G., Bouver, N., Shelton, J. R., Shelton, J. B., and Apell, G.: Nature of fetal hemoglobin in the Greek type of hereditary persistence of fetal hemoglobin with and without concurrent $\beta$-thalassemia. J. Clin. Invest., 49: 1035 (1970).

11. Schroeder, W. A., Bannister, W. H., Grech, J. L., Brown, A. K.,
Wrightstone, R. N., and Huisman, T. H. J.: Non-synchronized suppression of postnatal activity in non-allelic genes which synthesize the $\mathrm{G}_{\gamma}$ chain in human fetal hemoglobin. Nature New Biol., 244: 89 (1973).

12. Schroeder, W. A., Huisman, T. H. J., Brown, A. K., Uy, R., Bouver, N. G., Lerch, P. O., Shelton, J. R., Shelton, J. B., and Apell, G. Postnatal changes in the chemical heterogeneity of human feta hemoglobin. Pediat. Res., 5: 493 (1971).

13. Schroeder, W. A., Huisman, T. H. J., Shelton, J. R., Shelton, J. B. Apell, G., and Bouver, N.: Heterogeneity of fetal hemoglobin in $\beta$-thalassemia of the Negro. Amer. J. Hum. Genet., 22: 505 (1970).

14. Schroeder, W. A., Huisman, T. H. J., Shelton, J. R., Shelton, J. B., Kleihauer, E. F., Dozy, A. M., and Robberson, B.: Evidence for multiple structural genes for the $\gamma$ chain of human fetal hemoglobin. Proc. Nat. Acad. Sci: U. S. A., 60: 537 (1968).

15. Schroeder, W. A., Huisman, T. H. J., Shelton, J. R., and Wilson, J. B.: An improved method for the quantitative determination of human fetal hemoglobin. Anal. Biochem., 35: 235 (1970).

16. Schroeder, W. A., Shelton, J. R., Shelton, J. B., Apell, G., Huisman, T. H. J., and Bouver, N. G.: Worldwide occurrence of nonallelic genes for the $\gamma$ chain of foetal haemoglobin in newborns. Nature New Biol., 240: 273 (1972).

17. Sukumaran, P. K., Huisman, T. H. J., Schroeder, W. A., McCurdy, P. R., Freehafer, J. T., Bouver, N., Shelton, J. R., Shelton, J. B., and Apell, G.: A homozygote for the $\mathrm{HbG}_{\gamma}$ type of foetal haemoglobin in India: A study of two Indian and four Negro families. Brit. J. Haematol., 23: 403 (1972).

18. Wintrobe, M. M.: Clinical Hematology, Ed. 6 (Lea and Febiger, Philadelphia, 1967).

19. $\mathrm{G}_{\gamma}$ refers to the $\gamma$ chain with glycine in residue 136 and ${ }^{A_{\gamma}}$ refers to the $\gamma$ chain with alanine in this position. Chemical examination of $\mathrm{Hb}-\mathrm{F}$ and the determination of the residues of glycine and alanine in peptide $\gamma \mathrm{CB}-3$ which comprises the carboxy-terminal 13 residues of the $\gamma$ chain measure the ratio of the $G_{\gamma}$ and $A_{\gamma}$ chains. The value for glycine in $\gamma \mathrm{CB}-3$ is the easest indicator of the ratio of the two types. Thus, if glycine is one, only $\mathrm{G}_{\gamma}$ chains are being produced, and if glycine is 0 , only $\mathrm{A}_{\gamma}$ chains are produced. A nonintegral value of, for instance, 0.75 residue shows that both types are present and in a ratio of $0.75: 0.25$ or of $3: 1$. The $G_{\gamma}$ to $A_{\gamma}$ chain at birth averages $3: 1$ (6); however, with a further increase in the number of analyses the more accurate average ratio appears to be $7: 3$.

20. A detailed clinical description of these three patients is in preparation and will be presented elsewhere.

21. The authors are indebted to Nicole Bouver, Anne Brodie, J. Roger Shelton, Joan B. Shelton, and Gerald Apell for their technical assistance and to Dr. L. D. Sanghvi, Head, Epidemiology Division, Cancer Research Institute, Tate Memorial Center, Parel, Bombay-12 for his continued encouragement in this work. These studies were aided in part by grants HL-05168, HL-02558, and RR-86 (Clinical Research Center Grant) from the National Institutes of Health, United States Public Health Service and from funds from the Cooley's Anemia Blood and Research Foundation for Children, Inc., Southern California Chapter. This is Contribution no. 4821 from the Division of Chemistry and Chemical Engineering, California Institute of Technology.

22. Informed consent was obtained for all subjects in this study.

23. Requests for reprints should be addressed to: T. H. J. Huisman, Ph.D., D.Sc., Laboratory of Protein Chemistry, Medical College of Georgia, Augusta, Georgia 30902 (USA).

24. Accepted for publication April 26, 1974. 